\title{
Ham Petrol ve Benzin Fiyatlarının Sanayi Üretimine Etkisi: MS-VAR Modelleri ile Analizi
}

\author{
The Effects of Crude Oil Prices and Domestic Gasoline Prices on Industrial Production : \\ MS-VAR Analysis
}

Selin ÖZDEMIR', Işıl AKGÜL'1

\begin{abstract}
ÖZET
Bu makalenin amacı, Türkiye için ham petrol fiyatları ve benzin fiyatlarındaki ani değişimlerin sanayi üretimine etkisinin incelenerek literatüre katkı yapmaktır. Analizler 2005:10-2014:02 dönemi için değişkenlerin doğrusal olmayan özelliklerini yakalamakta başarılı olan Markov Değişim Vektör Otoregresif (MS-VAR) modelleri ile yapılmıştır. LR testi ile analiz döneminde iki rejim olduğu, ham petrol ve benzin fiyatlarındaki değişimin sanayi üretimine etkisinin bu rejimlere bağlı olarak değiştiği bulunmuştur. Ayrıca petrol ve benzin fiyatlarının sanayi üretimine geçiş etkisi olduğu ortaya konulmuştur.
\end{abstract}

Anahtar kelimeler: Ham petrol fiyatları, Benzin fiyatları, Sanayi üretim endeksi, MS-VAR Modeli, MS-ADF birim kök testi.

\section{Giriş}

Özellikle 1970'li yıllarda meydana gelen petrol şokları, ardından petrol fiyatlarındaki önemli dalgalanmaların oluşması, iktisatçılar ve politika yapıcıların petrol fiyatları ve ekonomik faaliyetler arasındaki ilişkiye dikkatlerini yoğunlaştırmalarına yol açmıştır. Bunun temel nedeni, sanayileşmiş veya gelişmekte olan ülke ayrımı yapılmaksızın, tüm ekonomiler için ham petrolün en önemli enerji kaynaklarından biri olmasıdır. Önemli bir girdi olması nedeni ile ham petrol fiyatlarının seyri yakından izlenmektedir.

Petrol fiyatlarında meydana gelen ani ve büyük değişmelerin, özellikle petrol ithal eden ülkelerde fiyat artışlarına yol açtığı, fiyat artışlarının enflasyon oranını arttırdığı ve ekonomik durgunluğa yol açtığı genel olarak kabul görmektedir. Bunun sebebi ise ham petrol fiyatlarının üretim aşamasında maliyet unsuru olarak yer alması ve firmaların ortaya çıkan fiyat değişikliklerini maliyetlerin içine katıp mark-up olarak bilinen fiyat ayarlaması yapmasıdır. Bu da sonuç olarak enflasyonist bir ortama neden olmaktadır.

Petrol fiyatlarındaki dalgalanmaların ekonomik büyüklüklere olduğu kadar makroekonomik politikalara da önemli etkisinin olduğu sıklıkla ifade edil-

\begin{abstract}
The purpose of this study is contribute to literature by studying the effects of sudden changes both on crude oil import prices and domestic gasoline prices on industrial production for Turkey. Analyses have been done in the period of 2005:10-2014:02 by Markov-switching vector autoregressive (MS-VAR) models which are successful to capture the nonlinear properties of variables. By using of LR test, it has been found that there are 2 regimes in the analysis period and it has been found that the effect of the changes of crude oil and domestic gasoline prices on industrial production differs according to these regimes. It has also been demonstrated that there is a passthrough effect from of oil and gas prices to industrial production.
\end{abstract}

Keywords: Crude oil prices, Gasoline prices, Industrial production index, MS-VAR Model, MS-ADF Unitroot test

mektedir. Bu etkiyi dikkatle izleyen kurumlardan biri de Türkiye Cumhuriyet Merkez Bankası (TCMB) dır. Tükettiği petrolün \%93'ünü ithalat yoluyla karşılayan Türkiye için ham petrol fiyatlarındaki değişim, 2005 yılından itibaren enflasyon hedeflemesi politikası uygulanması nedeni ile daha da önem kazanmıştır. Petrol fiyatlarında öngörülemeyen salınımların olmaSI, enflasyon hedefine ulaşılabilirlik açısından petrol fiyatlarını önemli bir risk unsuru haline getirmektedir.

Yukarıda anlatılanlar doğrultusunda bu makalede, ham petrol ve benzin fiyatlarındaki ani artışların sanayi üretimine etkisinin olup olmadığının, firmaların mark-up fiyatlama yapıp yapmadığının, bu fiyat artışlarının rejim değişikliklerine yol açıp açmadığının ve etkisi varsa ne şekilde etkilediğinin ortaya çıkarılması amaçlanmıştır. Çalışmada ham petrol fiyatlarının yanı sıra yurtiçi benzin fiyatlarının da sanayi üretimine etkisi araştırılmıştır. Petrol ve benzin fiyatlarının ayrı ayrı analiz edilmesinin nedeni, benzin fiyatlarının direkt ve endirekt vergi sebebiyle dünya ham petrol fiyatlarından ayrı fiyatlandırımasıdır. Bu farklılık nedeni ile yurtiçi benzin ve benzeri petrol ürünlerini kullanan sanayi dallarının benzin fiyatlarındaki ani değişikliklerden nasıl etkilendiğinin görülmesi amaçlanmıştır. 
Çalışmanın sonuçları aynı zamanda petrol ve benzin fiyat artışlarının sanayi kesimine endirekt etkisinin belirlenmesi açısından önemlidir. Fiyat artışlarının sanayi kesiminde nihai fiyatlara yansıtılması durumunda ürün fiyat artışı yolu ile genel fiyat düzeyinde artışa (endirekt etki) neden olacaktır. Bu da enflasyon hedeflemesi programı uygulayan bir ülkenin enflasyon hedeflerine olumsuz katkı yapacaktır.

Yazında petrol fiyatlarının GSYIH, enflasyon, sanayi üretimi gibi makroekonomik büyüklükler ile ilişkisini $A B D$ ve geliş̧miş ülkeler için inceleyen çalışmalara sık rastlanılmakla birlikte, bu ilişkiyi gelişmekte olan ülkeler için inceleyen çalışma sayısı azdır. Özellikle hem gelişmekte olan, hem de petrol ithalatçısı olan Türkiye için yapılan çalışma sayısı çok daha azdır. Ayrıca Türkiye için yapılan çalışmaların tümünde petrol ve benzin fiyatları ile sanayi üretimi arasındaki ilişkinin doğrusallık varsayımı altında incelendiği görülmektedir. Bu açıdan ele alındığında, Türkiye'de petrol ve benzin fiyatlarının sanayi üretimine etkisinin ortaya konulması ve aralarındaki ilişkinin doğrusal olup olmadığının incelenmesi, gelişmekte olan ve petrol üreticisi olan ülkeler açısından ayrıca önem taşımaktadır.

Çalışmanın içeriği şöyledir: Giriş bölümünü izleyen ikinci bölümde petrol, benzin fiyatları ve sanayi üretimi ile ilgili yazın taraması yapılmakta, üçüncü bölümde rejim değişim modellerinden Markov Değişim Vektör Otoregresif (MS-VAR) modeli anlatılmaktadır. Dördüncü bölüm, tahmin edilen modellerin ve etki tepki fonksiyonlarının analiz edilmesi ile öngörü sonuçlarının incelenmesini içeren uygulama bölümüdür. Çalışma, genel değerlendirme ile son bulmaktadir.

\section{Yazın Taraması}

Petrol fiyat şoklarının sanayi üretimi üzerine etkisini her dönem dikkat çeken konu başlıklarından olmuş ve bu amaçla çeşitli ülkeler için çalışmalar yapılmıştır. Mork ve Olson (1994), Amerika, Kanada, Japonya, Almanya, Fransa, Ingiltere ve Norveç'i kapsayan çalışmada Norveç dışındaki ülkeler için petrol fiyat artışı ile çıktı arasında negatif ve önemli bir ilişki olduğunu, ancak petrol fiyatlarının düşüşünün istatistiksel anlamlı bir katkısının olmadığını bulmuşlardır. Cuñado ve Pérez de Gracia (2003), 14 Avrupa ülkesi için petrol fiyat şoklarının endüstri üretimi ve tüketici fiyat endekslerine etkisini analiz ettikleri çalışmada, yapısal kırılmaya izin veren eştümleşme testi uygulamışlar ve olası doğrusal olmayan ilişkiyi dikkate almak için petrol fiyat verisine farklı dönüşümler yapmışlardır. Petrol fiyatlarının enflasyona sürekli etkisinin olduğunu ve üretim büyüme oranlarına kısa dönemli fakat asimetrik etkisinin olduğunu, ayrıca ülkelerin bu şoklara cevaplarında da anlamlı farklılık olduğunu ortaya koymuşlardır. Hamilton ve Herrara (2004), VAR analizi sonucunda, kapasite kullanımının, petrol fiyat şoklarına 1. ve 2. yılda pozitif tepki verirken 3. yıldan sonra negatif tepki verdiğini bulmuşlar; böylece kapasite kullanımını azalttığını, bunun da toplam endüstriyel çıktıda düşüşe yol açacağı şeklinde yorumlamışlardır. Reyes ve Quiros (2005), Amerika için Markov rejim değişim modeli ile yaptıkları analizde petrol fiyat artışının endüstriyel çıktıya etkisinin negatif ve istatistiksel anlamlı olduğu bulgusuna ulaşmışlardır. Cuñado ve Pérez de Gracia (2005), Asya ülkelerinde petrol fiyatı ile endüstriyel üretim arasında uzun dönemli eştümleşme olmadığını, kısa dönemde de etkisinin sınırlı olduğunu, ayrıca petrol fiyat şoklarının, çıktının Granger nedeni olduğunu ortaya koymuşlardır. Blanchard ve Gali (2007), Amerika, Fransa, Almanya, Ingiltere, İtalya ve Japonya için yapısal VAR analizi ile petrol fiyat değişmelerinin makroekonomik değişkenlere etkisini analiz etmişlerdir. Bulgular çıktı ve istihdam için tahmin edilen tepkinin zamanla zayıfladığını göstermiştir. Zhang (2008), 1957-2006 dönemi için petrol fiyat şoku ile Japon endüstriyel üretimi arasındaki ilişkiyi araştırmış ve aralarında doğrusal olmayan bir ilişkinin ortaya çıktığı sonucuna varmıştır. Jiménez-Rodríguez (2008), 6 OECD ülkesi için petrol fiyat şoklarının ürün çıktısına etkisini VAR modeli kullanarak analiz etmiş ve petrol fiyat şoklarının $A B D$ ve İngiltere için aynı olduğunu bulmuşlardır. Jiménez-Rodríguez ve Sánchez (2005), yaptıkları analiz sonucunda Japonya'da petrol fiyat şoklarının endüstriyel üretimde azalmaya ve enflasyonda artışa yol açtığını ve aralarındaki ilişkinin doğrusal olmadığını ortaya koymuşlardır. Fukunaga, Hirakata ve Sudo (2010), VAR modeli ile petrol fiyatındaki değişimlerin endüstriyel üretimin her bir bileşimine etkisini araştırmış ve petrol fiyat değişmelerinin etkilerinin endüstrinin özelliklerine göre değiştiğini söylemişleridir. Herrera, Lagalo ve Wada (2011), ABD için petrol fiyat şoklarının endüstriyel üretim ve sektörel bileşenlerine etkisi araştırmışlar, reel petrol fiyat şoklarına endüstrinin tepkisinin asimetrik olduğunu ortaya koymuşlardır. Sektörlerin ayrıştırıldığı durumda, özellikle enerji-yoğun üretim yapan endüstrilerde asimetri için güçlü destek bulmuşlardır. Kilian ve Vigfusson (2011) Amerika için petrol fiyat şoklarının çıktıya geçişinde asimetri etkisi olduğunu destekleyen bulgulara ulaşmışlardır. Ashley ve Tsang (2013) net petrol ithalatçısı olan 6 ülke için petrol fiyatlarındaki değişmenin çıktı büyümesine etkisini zaman serilerini frekanslarına göre ayrıştırmışlar ve petrol fiyat değişmelerinin 4 yıldan daha sürekli olması durumunda gelecek çıktı büyümesine büyük ve istatistiksel anlamlı etkisi olduğunu, 4 yıldan az ama 1 yıldan daha 
uzun değişikliklerin ise çıktı büyümesine anlamlı etkisinin olmadığını ortaya koymuşlardır. 1 yıldan az, geçici dalgalanma durumunda ise büyük ve istatistiksel anlamlı etkisi sonucuna varmışlardır.

Türkiye için petrol fiyatlarının çeşitli makroekonomik değişkenler üzerindeki etkisini araştıran çalışmaların olduğu ancak bunların daha çok enflasyon ve büyüme ile ilgili olduğu görülmüştür. Bu çalışmalarda da genel olarak nedensellik, VAR analizi ve eştümleşme analizinden yararlanıldığı görülmüştür. Sonuç olarak çalışmalarda petrol fiyatları ile ekonomik faaliyet arasındaki ilişkinin doğrusal olduğu varsayılarak petrol etkisinin araştırıldığı görülmektedir.

Alper ve Torul (2008), dünya petrol fiyatlarındaki değişmelerin imalat sanayi alt sektörlerine etkisini VAR modeli ile analiz ederek ne ham petrol ne de petrol ürün fiyatlarındaki artışın Türkiye'de toplam üretim büyümesini engellemediğini; ancak petrol ürün fiyat artışlarının odun ve odun ürünleri, plastik ürünler gibi birkaç alt sektörde üretim büyümesini engellediğini bulmuşlardır. Ekşi, İzgi ve Şentürk (2011), ham petrol fiyatları ve endüstriyel üretim arasında nedensellik ilișkisi olduğunu ortaya koymuşlardır. Yaylalı ve Lebe (2012), ham petrol fiyatı, sanayi üretim endeksi, bankalar arası faiz oranı, enflasyon oranı ve para arzı arasındaki ilişkiyi VAR modeli ile incelemişler, sanayi üretim endeksinin, petrol fiyat artışından gelen şoklara 2., 5. ve 7. dönemde pozitif tepki verdiği bulgusuna ulaşmışlardır. Barışık ve Yayar (2012) petrol fiyatları, döviz kuru, ihracat gibi dışsal faktörlerin, kamu harcaması, tüketim harcaması, ithalat gibi içsel faktörlerin sanayi üretim endeksini etkilediğini VAR analizi ile ortaya koymuşlardır.

Yukarıda da değinildiği üzere, Türkiye için yapılan çalışmalar incelendiğinde olası doğrusal olmayan yapının ihmal edildiği, değişkenlerin aralarındaki ilişkinin farklı rejimler için incelenmediği ve öngörü yapılmadığı görülmektedir. Bu çalışma, ham petrol fiyatları ve benzin fiyatlarının sanayi üretim endeksine etkisinin doğrusal olmayan MS-VAR modeli ile modellenmesi, farklı rejimler için etki tepki fonksiyonlarının incelenmesi ve öngörü yapılması bakımından diğer çalışmalardan önemli derecede farklılaşmaktadır.

\section{MS-VAR Modeli}

Son yıllarda ekonomik ve finansal zaman serisi analizlerinde rejim değişim tipi doğrusal olmayan modeller sıklıkla kullanılmaya başlanmıştır. Zaman serileri için Markov rejim değişim modelleri Hamilton (1988) ve Hamilton (1989) çalışmaları ile tanıtılmış, temel katkı ise, Krolzig (1997) tarafından yapılmıştır. Krolzig çalışmasında MS-VAR modellerini sınıflandırarak genişletmiştir. Daha sonra Krolzig (1998, 2000,
2001, 2006) çalışmaları ile de anılan modelleri dinamik çok değişkenli sistemlere uyarlamıştır. Krolzig (2006:2) MS-VAR modelini

$$
\begin{aligned}
& y_{t}=v\left(s_{t}\right)+A_{1}\left(s_{t}\right) y_{t-1}+\ldots+A_{p}\left(s_{t}\right) y_{t-p}+u_{t}, \\
& u_{t} / s_{t} \sim \operatorname{NID}\left(0, \sum\left(s_{t}\right)\right)
\end{aligned}
$$

şeklinde yapmış ve modelde yer alan $v\left(s_{t}\right)$, $A_{1}\left(s_{t}\right)+\ldots+A_{p}\left(s_{t}\right)$ ve $\sum\left(s_{t}\right)$ parametrelerinin $s_{t}$ rejimine bağımlıı̆ı̆ını,

$$
v\left(s_{t}\right)=\left\{\begin{array}{cc}
v_{1} & \text { eger } s_{t}=1, \\
\vdots & \\
v_{M} & \text { eger } s_{t}=M .
\end{array}\right.
$$

olarak göstermiştir. Genelleştirilmiş etki tepki analizi çerçevesinde $h$ periyodunda değişkenlere uygulanan şoklara sistemin verdiği tepki aşağıda verilmiştir.

$$
E T_{\nabla U}(h)=E\left[y_{t+h} \mid \xi_{t}, u_{t} ; \nabla u ; Y_{t-1}\right]
$$

Eşitlikte yer alan $\nabla u, t$ zamanındaki şoku göstermektedir. Rejim değişimlerine olan genelleştirilmiş etki tepki ise,

$$
E T_{\nabla \xi}(h)=E\left[y_{t+h} \mid \xi_{t}+\nabla \xi, u_{t} ; Y_{t-1}\right]-E\left[y_{t+h} \mid \xi_{t}, u_{t} ; Y_{t-1}\right]
$$

şeklinde tanımlanmaktadır. Burada $\nabla \xi, t$ zamanındaki rejim değişimini ifade etmektedir. Krolzig (2006:7) rejime bağlı olmayan otoregresif dinamiklere sahip MS-VAR modellerinde etki tepki fonksiyonlarını

$$
\begin{gathered}
y_{t}=\left(y_{t}^{\prime}, \ldots, y_{t-p+1}^{\prime}\right)^{\prime} \text { iken MS(M)-VAR(1) modeli için, } \\
y_{t}=H \xi_{t}+A y_{t-1}+u_{t}
\end{gathered}
$$

ile göstermiştir. Modelde $\left\{u_{t}, \xi_{t}, Y_{t-1}\right\}$ 'e koşullu olarak, $y_{t+h}$ 'nin beklenen değeri $y_{t+h \mid t}=H \xi_{t+h \mid t}+A_{t+h-1 \mid t}$ şeklindeyken, $\xi_{t}$ 'nin koşullu beklentisi ise $\xi_{t+h \mid t}=F^{h} \xi_{t}$ şeklindedir. Rejimdeki kaymaların etkileri, $t$ anında rejimdeki bir değişmeye $y_{t+h}$ 'nin bir tepkisi olarak ölçülebilir. Bu durumda,

$$
E T_{\nabla \xi}(h)=J\left(\sum_{k=0}^{h} A^{k} H F^{h-k}\right) \nabla \xi
$$

etki tepki fonksiyonunu tanımlar. Burada $J\left(I_{K} 0 \ldots 0\right) 7=i_{1}^{\prime} \otimes I_{k}, \quad i_{j}$ birim matrisin $j$ 'inci sütunu olmak üzere $\left(K \times K_{p}\right)^{j}$ boyutlu bir matristir. Krolzig (2006:6) rejime bağlı otoregresif dinamik MSA(M)VAR(1) modelinin gösterimini, 


$$
\begin{aligned}
& y_{t}=A\left(\xi_{t}\right) y_{t-1}+u_{t}, \\
& \xi_{t}=F \xi_{t-1}+v_{t} .
\end{aligned}
$$

ile yapmıştır. Modelde $u_{t} \sim \operatorname{NID}(0, \Sigma)$ ve $v_{t}$ bir martingale fark dizisidir ve $y_{t}=\sum_{i=1}^{M} \xi_{i t} y_{t}$ olduğundan $y_{t+h}$ 'nin koşullu beklentisi,

$E\left[y_{t+h} \mid y_{t}, \xi_{t}\right]=\sum_{i=1}^{M} E\left[\xi_{i t+h} y_{t+h} \mid y_{t}, \xi_{t}\right]=\left(1_{M}^{\prime} \otimes I_{K}\right) E\left[\gamma_{t+h} \mid \gamma_{t}\right]=$

$\left(1_{M}^{\prime} \otimes I_{K}\right) \prod^{h}\left(\xi_{t} \otimes y_{t}\right)$

şeklindedir. Etki tepkiler ise,

$$
\begin{aligned}
& E T_{\nabla U}(h)=\left(1_{M}^{\prime} \otimes I_{K}\right) \prod^{h}\left(\xi_{t} \otimes \nabla u\right), \\
& E T_{\nabla \xi}(h)=\left(1_{M}^{\prime} \otimes I_{K}\right) \prod^{h}\left(\nabla \xi_{t} \otimes y_{t}\right) .
\end{aligned}
$$

ile gösterilir.

Hamilton (1989) MS-VAR modelinin tahmin edilmesi için iki basamaklı bir algoritma tanıtmıştır. illk basamakta gözlemlenmemiş rejimlerin bileşik olasılık yoğunlukları da dahil olmak üzere ana kütle parametreleri tahmin edilmektedir. İkinci aşamada ise doğrusal olmayan filtreleme ve düzleştirmeler kullanılarak gözlemlenmemiş rejimler hakkında çıkarsamada bulunulmaktadır.

Hamilton modeli parametrelerinin tahmin süreci, log-olabilirlik fonksiyonunun maksimize edilmesi ile tahmin edilen parametrelerin kullanılarak gözlenmemiş rejim değişkeni $s_{t}$ için filtrelenmiş ve düzleştirilmiş olasılıkları bulmaya dayanır. Tahmin edilen parametre sayısının çok olması durumunda da Dempster, Laird ve Rubin (1977) tarafından tanıtılan Beklenti Maksimizasyonu (EM) algoritmasının kullanılması önerilmektedir.

\section{Uygulama}

Çalışmada, 2005:10 to 2014:02 dönemi için Federal Reserve Bank of St Louis veri dağıtım sitesinden alınan ham petrol fiyatları (Brent-\$/barrel) ( $P E T$ ), OPET'ten alınan benzin fiyatları (\$/barrel) ( $B E N)$ ve TÜiK'ten alınan sanayi üretim endeksi ( $S \ddot{U} E$ ) verileri kullanılmıştır. Serilere varyansta durağan olmama problemine karşı logaritmik dönüşüm yapılmıştır. Daha sonra durağanlıkları incelenmiş ve durağan olmadıkları görülen serilerin farkı alınmıştır. TCMB'nin 2006 yılından itibaren açık enflasyon hedeflemesi politikası uygulamaya başlaması nedeniyle 2006 yılının analizde başlangıç yılı olarak seçilmesi düşünülmüş, ancak veri kaybını önlemek amacı ile 2005:10 tarihi seçilmiştir. Analize serilere ait bazı istatistiklerin hesaplanması ve durağanlığın test edilmesi ile başlanmış, elde edilen sonuçlar Tablo 1'de verilmiştir.
Tablo 1: Serilerin bazı tanımsal istatistikleri

\begin{tabular}{llll}
\hline & $\Delta L S \ddot{U} E$ & $\Delta L P E T$ & $\Delta L B E N$ \\
Standart Sapma & 11.68 & 1.77 & 0.76 \\
Eğiklik (SK) & -0.12 & -0.06 & 0.28 \\
Basıklık (K) & 2.78 & 1.76 & 1.66 \\
Jarque-Bera (JB) & 0.46 & 6.51 & 8.87 \\
MS-ADF & -6.45 & -6.28 & -7.14 \\
& $(0.01)$ & $(0.02)$ & $(0.00)$ \\
\hline \multicolumn{2}{c}{$* \% 5$ istatiksel anlamllık düzeyini göstermektedir. }
\end{tabular}

*\%5 istatiksel anlamlılık düzeyini göstermektedir.

Tablo 1'de JB test istatistiği sonuçlarına göre $\triangle L S \ddot{U} E$ serisi normal dağılırken $\triangle L P E T$ ve $\triangle L B E N$ serilerinin normal dağılmadığı görülmektedir. Serilerin durağanlıkları incelenirken Hall, Psaradakis ve Sola (1999) tarafından ortaya konulan MS-ADF birim kök testinden yararlanılmış, test sonuçlarına göre logaritmik fark serilerinin tümünün durağan olduğu ortaya konulmuştur. Ardından model seçiminin ilk aşaması olan modellerin rejim sayısını belirlemek amacı ile LR testi uygulanmış, doğrusal VAR modeli, 2 rejimli MSVAR modeline karşı, 2 rejimli MS-VAR modeli, 3 rejimli MS-VAR modeline karşı sınanmış sonuçlar Tablo 2'de verilmiştir.

Tablo 2: LR test sonuçları

\begin{tabular}{lcc}
\hline \multicolumn{2}{l}{ LR Testi Sonuçları } & \\
\hline Önsav & $\Delta L S \ddot{U} E-\triangle L P E T$ & $\Delta L S \ddot{U} E-\Delta L B E N$ \\
$\begin{array}{l}\text { Ho:Doğrusal } \\
\text { VAR }\end{array}$ & $34.12^{*}$ & $37.41^{*}$ \\
Ha:Iki Rejimli & $(0.02)$ & $(0.02)$ \\
MS-VAR & & \\
$\begin{array}{l}\text { Ho:İki Rejimli } \\
\text { MS-VAR } \\
\text { Ha:Üç Rejimli } \\
\text { MS-VAR }\end{array}$ & 4.13 & 4.53 \\
\hline
\end{tabular}

*\%5 istatiksel anlamlılık düzeyini göstermektedir.

İlk basamakta doğrusal VAR modeli, iki rejimli MS-VAR modeli alternatifine karşı test edilmiş ve doğrusal VAR modelinin doğru olduğunu ifade eden Ho hipotezi reddedilmiştir. İkinci basamakta ise iki rejimli MS-VAR modeli üç rejimli MS-VAR modeli alternatifine karşı test edilmiş ve iki rejimli MS-VAR modelinin doğru olduğunu ifade eden Ho hipotezi reddedilememiş ve iki rejimin varlığı ortaya konulmuştur. Çalışmada rejim 1 kriz dönemini, rejim 2 büyüme dönemini açıklamaktadır. Daha sonra Schwarz bilgi kriteri (SC) ile gecikme uzunlukları belirlenmiş, $\triangle L S \ddot{U} E-\triangle L P E T$ ve $\triangle L S \ddot{U} E-\triangle L B E N$ için $\mathrm{MSIH}(2)$ $\operatorname{VAR}(7)$ modelinin uygun olduğu sonucuna varılmıştır. $\triangle L S \ddot{U} E-\triangle L P E T$ için tahmin edilen model Tablo 3'te verilmiştir. 
Tablo 3: $\triangle L S \ddot{U} E-\triangle L P E T$ için MSIH(2)-VAR(7) modeli

\begin{tabular}{|c|c|c|c|c|}
\hline & \multicolumn{2}{|c|}{$\Delta L S \ddot{U} E$} & \multicolumn{2}{|c|}{$\triangle L P E T$} \\
\hline Sabit(Rej.1) & \multicolumn{2}{|c|}{$\begin{array}{l}0.007 \\
(0.79)\end{array}$} & \multicolumn{2}{|c|}{$\begin{array}{l}-0.016 \\
(-0.86)\end{array}$} \\
\hline Sabit(Rej.2) & \multicolumn{2}{|c|}{$\begin{array}{l}0.004 \\
(0.40)\end{array}$} & \multicolumn{2}{|c|}{$\begin{array}{l}0.024 \\
(3.55)^{*}\end{array}$} \\
\hline$\Delta L S \ddot{U} E_{t-1}$ & \multicolumn{2}{|c|}{$\begin{array}{l}-0.752 \\
(-6.53)^{*}\end{array}$} & \multicolumn{2}{|c|}{$\begin{array}{l}-0.043 \\
(-0.40)\end{array}$} \\
\hline$\Delta L S \ddot{U} E_{t-2}$ & \multicolumn{2}{|c|}{$\begin{array}{l}-0.521 \\
(-3.94)^{*}\end{array}$} & \multicolumn{2}{|c|}{$\begin{array}{l}-0.173 \\
(-1.53)\end{array}$} \\
\hline$L S \ddot{U} E$ & \multicolumn{2}{|c|}{$\begin{array}{l}-0.328 \\
(-2.80)^{*}\end{array}$} & \multicolumn{2}{|c|}{$\begin{array}{l}-0.173 \\
(-1.21)\end{array}$} \\
\hline$\Delta L S \ddot{U} E_{t-4}$ & \multicolumn{2}{|c|}{$\begin{array}{l}0.044 \\
(0.39)\end{array}$} & \multicolumn{2}{|c|}{$\begin{array}{l}-0.233 \\
(-1.96)^{*}\end{array}$} \\
\hline$\Delta L S \ddot{U} E_{t-5}$ & \multicolumn{2}{|c|}{$\begin{array}{c}0.251 \\
(3.27)^{*}\end{array}$} & \multicolumn{2}{|c|}{$\begin{array}{l}0.188 \\
(1.56)\end{array}$} \\
\hline$\Delta L S \ddot{U} E_{t-6}$ & \multicolumn{2}{|c|}{$\begin{array}{l}0.013 \\
(0.15)\end{array}$} & \multicolumn{2}{|c|}{$\begin{array}{l}-0.091 \\
(-0.68)\end{array}$} \\
\hline$\Delta L S \ddot{U} E_{t-7}$ & \multicolumn{2}{|c|}{$\begin{array}{l}0.333 \\
(4.15)^{*}\end{array}$} & \multicolumn{2}{|c|}{$\begin{array}{l}0.112 \\
(1.53)\end{array}$} \\
\hline$\Delta L P E T_{t-1}$ & \multicolumn{2}{|c|}{$\begin{array}{l}-0.427 \\
(-3.22)^{*}\end{array}$} & \multicolumn{2}{|c|}{$\begin{array}{l}-0.105 \\
(-0.76)\end{array}$} \\
\hline$\triangle L P E T_{t-2}$ & \multicolumn{2}{|c|}{$\begin{array}{l}-0.424 \\
(-3.43)^{*}\end{array}$} & \multicolumn{2}{|c|}{$\begin{array}{l}-0.026 \\
(-0.20)\end{array}$} \\
\hline$\Delta L P E T_{t-3}$ & \multicolumn{2}{|c|}{$\begin{array}{l}0.154 \\
(1.83)\end{array}$} & \multicolumn{2}{|c|}{$\begin{array}{l}-0.117 \\
(-1.20)\end{array}$} \\
\hline$\Delta L P E T_{t-4}$ & \multicolumn{2}{|c|}{$\begin{array}{l}0.122 \\
(1.95)\end{array}$} & \multicolumn{2}{|c|}{$\begin{array}{l}0.329 \\
(2.31)^{*}\end{array}$} \\
\hline$\triangle L P E T_{t-5}$ & \multicolumn{2}{|c|}{$\begin{array}{l}0.020 \\
(0.23)\end{array}$} & \multicolumn{2}{|c|}{$\begin{array}{l}0.038 \\
(0.44)\end{array}$} \\
\hline$\Delta L P E T_{t-6}$ & \multicolumn{2}{|c|}{$\begin{array}{l}-0.072 \\
(-0.85)\end{array}$} & \multicolumn{2}{|c|}{$\begin{array}{l}-0.140 \\
(-1.81)\end{array}$} \\
\hline$\triangle L P E T_{t-7}$ & \multicolumn{2}{|c|}{$\begin{array}{l}-0.127 \\
(-1.69) \\
\end{array}$} & \multicolumn{2}{|c|}{$\begin{array}{l}0.013 \\
(0.15)\end{array}$} \\
\hline Standart Hata (Rej.1) & & & & \\
\hline Standart Hata (Rej.2) & & & & \\
\hline $\begin{array}{l}\text { Vector portmanteau(24): } \\
\text { chi(68) }\end{array}$ & & & Chi $(6$ & \\
\hline Vector normality test: Chi(4) & & & & \\
\hline Vector hetero test: Chi(84) & & & Chi & \\
\hline LR linearity test: Chi(5) & & & DAVIE & \\
\hline Geçiş olasılıkları & Rejim 1 & Rejim 2 & Gözlem sayısı & Süre \\
\hline Rejim 1 & 0.76 & 0.24 & 45.7 & 4.21 \\
\hline Rejim 2 & 0.22 & 0.78 & 48.3 & 4.58 \\
\hline
\end{tabular}

*\%5 istatiksel anlamlılık düzeyini göstermektedir.

Modelin tahmini sonrasında vektör portmanto, vektör normallik ve vektör farklı yayılım testleri yapılmış ve model artıklarının; normal dağılıma sahip, otokorelasyonsuz ve eşit yayılımlı olduğu ortaya konmuştur. VAR temelli modellerde genel olarak parametrelerin istatistiksel anlamlılığı, işaretleri, büyüklüğünün dikkate alınmamaktadır. Krolzig (1998)'de katsayıların istatistiksel anlamlıı̆̆ı ve işaretlerinin yorumlanması- nın gereksiz olduğunu vurgulamıştır. Ancak katsayılarının işaretlerinin ilişkinin yönü, istatistiksel önemi ve büyüklüklerinin yön gösterici olacağı görüşü ile bazı noktalara değinilmesinin yararlı olduğu düşünülerek bilgi verilmiştir. Katsayılar incelendiğinde $\triangle L P E T$ 'deki değişmelerin $\triangle L S U ̈ E$ 'ye etkisinin 1 ve 2. dönemlerde negatif ve istatistiksel anlamlı olduğu; 3 ve 4 . dönemlerde pozitif ve istatistiksel anlamlı olduğu; 5 ve 6 . 
dönemlerde istatistiksel anlamsız olduğu; 7. dönemde negatif ve istatistiksel anlamlı olduğu görülmektedir. Negatif yönlü etki, petrol fiyatlarındaki değişmeye sanayinin ilk 2 ayda uyum sağlayamadığını ve azalma yönünde tepki verdiğini göstermektedir. Ancak 3. dönemden itibaren etkinin yönü pozitif olmaktadır. Bu da gecikme etkisi ile sanayi üretiminde mark-up fiyatlaması uyguladığının bir göstergesi olarak kabul edilebilir. Modelin standart hataları incelendiğinde kriz dönemi olan rejim 1'de $\triangle L P E T$ 'in oynaklığının, $\triangle L S U ̈ E$ 'ne göre daha fazla, ancak büyüme dönemi olan rejim 2'de $\triangle L S U ̈ E$ 'nin oynaklığından daha fazla olduğu görülmektedir. Geçiş olasılıkları incelendiğinde Rejim 1'de iken ertesi dönem aynı rejimde kalma olasılığının 0.76 , rejim 2'de iken ertesi dönem aynı rejimde kalma olasılığı, 0.78 rejim 1 'de iken ertesi dönem Rejim 2'ye geçme olasılığı 0.24, rejim 2'de iken ertesi dönem rejim 1'e geçme olasıllı̆̆ 0.22 'dir. Bulgular kriz ve büyüme rejimlerinde kalma olasılıklarının benzer olduğunu göstermektedir. Rejimler arasındaki geçiş olasılıkları da yaklaşık aynıdır. Rejim gözlem sayıları ve ortalama süre her iki rejiminde eşit ağırlıkta olduğunu desteklemektedir. Kriz de kalma süresi 4.21 ay, büyüme rejiminde kalma süresi 4.58 aydır. Burada ortalama sürelerin 4 ay arasında olması, evre sayısını çoğaltmaktadır. Evre sayısının çokluğu, hızlı geçişlerin olduğunu, bir rejimde kalma süresinin kısa olduğunu göstermektedir. Tahmin edilen modelin katsayıları ve geçiş olasılıkları incelendikten sonra rejim geçiş grafiği Şekil 1'de verilmiştir.

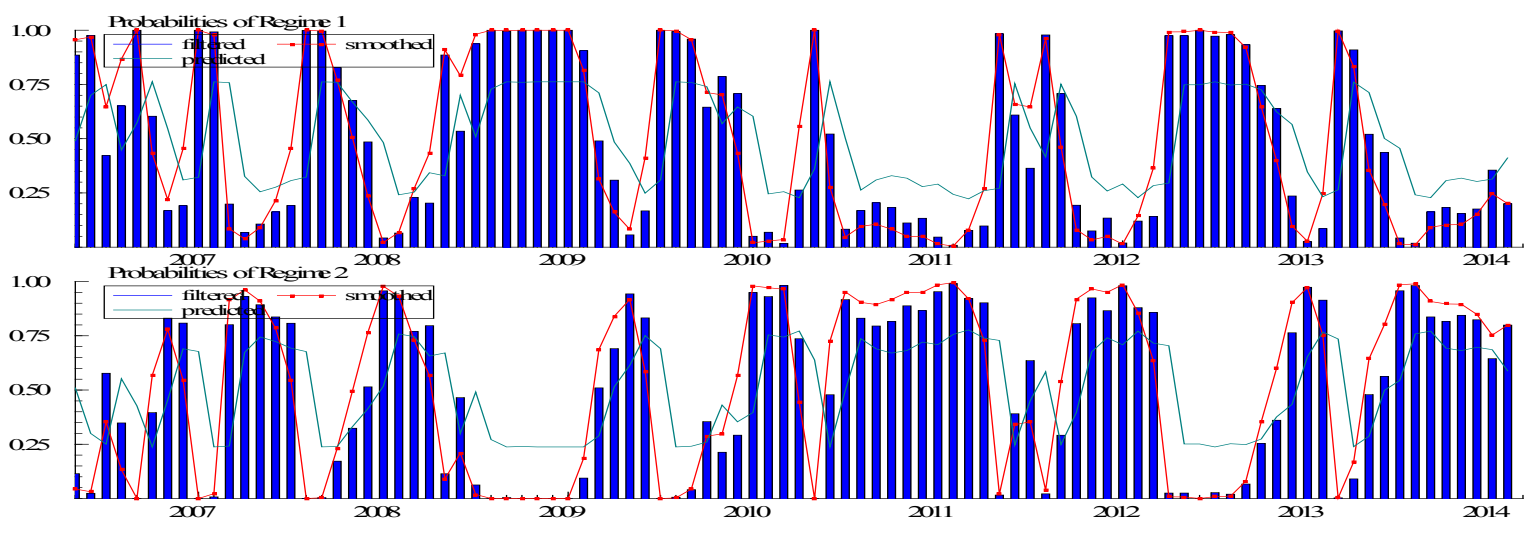

Şekil 1: $\triangle L S U ̈ E-\triangle L P E T$ için rejim grafiği

Grafikler bir arada ele alındığında; petroldeki yüksek oynaklıkların kriz rejimi, düşük oynaklığın ise büyüme rejimi tarafından yakalandığı görülmektedir. Sanayi açısından bakıldığında da sanayi üretiminde düşüşleri kapsayan 1. rejim kriz, artışları kapsayan 2. rejim büyüme rejimine karşı gelmektedir. Bu durum kriz rejiminde, krizin petrol fiyatlarından kaynaklanması nedeniyle petrol fiyatlarının oynaklığının fazla, ikinci rejimde petrol fiyatlarının oynaklığının düştüğünü ortaya koymaktadır. Petrol fiyatlarının oynaklığı düşerken, kriz rejiminden büyüme rejimine geçen ekonomide üretim artmakta, bu sebeple sanayi üretiminin oynaklığı artmaktadır. Rejim grafikleri incelendikten sonra $\triangle L S U ̈ E-\triangle L B E N$ için tahmin edilen model Tablo 4'te verilmiştir. 
Tablo 4: $\triangle L S \ddot{U} E-\triangle L B E N$ için MSIH(2)-VAR(7) modeli

\begin{tabular}{|c|c|c|c|c|}
\hline & \multicolumn{2}{|c|}{ SÜE } & \multicolumn{2}{|c|}{ PET } \\
\hline Sabit(Rej.1) & \multicolumn{2}{|c|}{$\begin{array}{l}-0.017 \\
(-3.94)^{*} \\
\end{array}$} & \multicolumn{2}{|c|}{$\begin{array}{l}-0.006 \\
(-0.72)\end{array}$} \\
\hline Sabit(Rej.2) & \multicolumn{2}{|c|}{$\begin{array}{l}0.000 \\
(0.03) \\
\end{array}$} & \multicolumn{2}{|c|}{$\begin{array}{c}0.016 \\
(4.94)^{*} \\
\end{array}$} \\
\hline$\Delta L S \ddot{U} E_{t-1}$ & \multicolumn{2}{|c|}{$\begin{array}{l}-0.507 \\
(-9.03)^{*}\end{array}$} & \multicolumn{2}{|c|}{$\begin{array}{l}-0.066 \\
(-1.57) \\
\end{array}$} \\
\hline$\Delta L S \ddot{U} E_{t-2}$ & \multicolumn{2}{|c|}{$\begin{array}{l}0.027 \\
(0.48) \\
\end{array}$} & \multicolumn{2}{|c|}{$\begin{array}{l}-0.003 \\
(-0.06) \\
\end{array}$} \\
\hline$\Delta L S \ddot{U} E_{t-3}$ & \multicolumn{2}{|c|}{$\begin{array}{c}-0.236 \\
(-3.58)^{*} \\
\end{array}$} & \multicolumn{2}{|c|}{$\begin{array}{l}0.073 \\
(1.46) \\
\end{array}$} \\
\hline$\Delta L S \ddot{U} E_{t-4}$ & \multicolumn{2}{|c|}{$\begin{array}{c}-0.312 \\
(-5.78)^{*} \\
\end{array}$} & \multicolumn{2}{|c|}{$\begin{array}{l}0.052 \\
(1.04) \\
\end{array}$} \\
\hline$\Delta L S \ddot{U} E_{t-5}$ & \multicolumn{2}{|c|}{$\begin{array}{c}-0.345 \\
(-6.38)^{*}\end{array}$} & \multicolumn{2}{|c|}{$\begin{array}{l}-0.066 \\
(-1.30)\end{array}$} \\
\hline$\Delta L S \ddot{U} E_{t-6}$ & \multicolumn{2}{|c|}{$\begin{array}{l}0.052 \\
(0.98)\end{array}$} & \multicolumn{2}{|c|}{$\begin{array}{l}-0.014 \\
(-0.29)\end{array}$} \\
\hline$\Delta L S \ddot{U} E_{t-7}$ & \multicolumn{2}{|c|}{$\begin{array}{l}0.203 \\
(5.38)\end{array}$} & \multicolumn{2}{|c|}{$\begin{array}{l}0.020 \\
(0.51)\end{array}$} \\
\hline$\triangle L B E N_{t-1}$ & \multicolumn{2}{|c|}{$\begin{array}{c}0.299 \\
(2.64)^{*}\end{array}$} & \multicolumn{2}{|c|}{$\begin{array}{l}0.025 \\
(0.31)\end{array}$} \\
\hline$\triangle L B E N_{t-2}$ & \multicolumn{2}{|c|}{$\begin{array}{c}0.420 \\
(5.31)^{*}\end{array}$} & \multicolumn{2}{|c|}{$\begin{array}{l}0.217 \\
(2.65)^{*}\end{array}$} \\
\hline$\Delta L B E N_{t-3}$ & \multicolumn{2}{|c|}{$\begin{array}{c}0.471 \\
(5.20)^{*}\end{array}$} & \multicolumn{2}{|c|}{$\begin{array}{c}-0.211 \\
(-2.48)^{*}\end{array}$} \\
\hline$\triangle L B E N_{t-4}$ & \multicolumn{2}{|c|}{$\begin{array}{l}0.184 \\
(1.90) \\
\end{array}$} & \multicolumn{2}{|c|}{$\begin{array}{l}-0.118 \\
(-1.37) \\
\end{array}$} \\
\hline$\triangle L B E N_{t-5}$ & \multicolumn{2}{|c|}{$\begin{array}{l}0.448 \\
(4.39)\end{array}$} & \multicolumn{2}{|c|}{$\begin{array}{l}0.112 \\
(1.23)\end{array}$} \\
\hline$\triangle L B E N_{t-6}$ & \multicolumn{2}{|c|}{$\begin{array}{l}0.027 \\
(0.22)\end{array}$} & \multicolumn{2}{|c|}{$\begin{array}{l}-0.173 \\
(-2.04)\end{array}$} \\
\hline$\triangle L B E N_{t-7}$ & \multicolumn{2}{|c|}{$\begin{array}{l}-0.172 \\
(-2.37)\end{array}$} & \multicolumn{2}{|c|}{$\begin{array}{l}-0.214 \\
(-2.32)\end{array}$} \\
\hline Standart Hata (Rej.1) & & & & \\
\hline Standart Hata (Rej.2) & & & & \\
\hline Vector portmanteau(24): chi(68) & & & Chi ( & \\
\hline Vector normality test: Chi(4) & & & & \\
\hline Vector hetero test: Chi(84) & & & Chi $(8$ & \\
\hline LR linearity test: Chi(5) & & & Davie & \\
\hline Geçiş olasılıkları & Rejim 1 & Rejim 2 & Gözlem sayısı & Süre \\
\hline Rejim 1 & 0.52 & 0.48 & 33.6 & 2.06 \\
\hline Rejim 2 & 0.27 & 0.73 & 60.4 & 3.72 \\
\hline
\end{tabular}

*\%5 istatiksel anlamlııı düzeyini göstermektedir 
Bu modelin tahmini sonrasında da vektör portmanto, vektör normallik ve vektör farklı yayılım testleri yapılmış ve model artıklarının; normal dağılıma sahip, otokorelasyonsuz ve eşit yayılımlı olduğu ortaya konulmuştur. Tablo 4'te verilen katsayılar incelendiğinde benzin fiyatlarındaki değişmelerin $\Delta L S U ̈ E$ 'ye 1. dönemden başlamak üzere 5 dönem boyunca pozitif ve istatistiksel anlamlı etkisinin olduğu, sadece 7. dönemde negatif yönlü ve önemli etkisi olduğunu görülmektedir. Bu sonuç sanayinin benzin fiyatlarındaki değişikliğe hemen mark-up fiyatlaması yaparak tepki verdiğini, ancak 7. dönemde üretimde bir daralma başladığını göstermektedir. Bu sonuç ile firmaların mark-up fiyatlaması uygulaması nedeni ile benzin fiyatlarındaki ani artışlarının $\triangle L S \ddot{U} E$ üzerinde azaltıcı bir etkisinin olmadığı, hatta tam tersi pozitif yönlü ilişki olduğu ortaya çıkmıştır. Modelin standart hataları $\triangle L B E N$ 'in rejim 1'de oynaklığının, $\triangle L S U ̈ E$ 'nin oynaklığına göre daha fazla olduğunu, 2. rejimde ise $\triangle L S \ddot{U} E$ 'nin oynaklığının, $\triangle L B E N$ 'nin 4 katı olduğunu ortaya koymaktadır. Geçiş olasılıkları incelendiğinde rejim 1'de iken ertesi dönem aynı rejim- de kalma olasılığının 0.52, rejim 2'de iken ertesi dönem aynı rejimde kalma olasıı̆ğının 0.73 , rejim 1 'de iken ertesi dönem rejim 2'ye geçme olasılığının 0.48 , rejim 2'de iken ertesi dönem rejim 1'e geçme olasılığının 0.27 olduğu görülmektedir. Bulgular büyüme rejiminde kalma olasılığının daha yüksek olduğunu göstermektedir. Ayrıca kriz rejiminden büyüme rejimine geçiş olasılığı da oldukça yüksektir. Büyüme rejiminde kalma olasılığının yüksek olması, bu rejimin kararlılığını göstermektedir. Rejim gözlem sayıları ve ortalama süre rejim 2'nin daha hakim olduğunu göstermektedir. Kriz rejiminde kalma süresi 2.06 ay, büyüme rejiminde kalma süresi 3.72 aydır. Burada sürelerin krizde 2 ay, büyümede yaklaşık 4 ay olması, rejim evre sayısının 2 rejimde farklı olmasına neden olmaktadır. Kriz rejiminde bulunduğu sırada ortalama 2 ay gibi bir sürede, hızla mark-up fiyatlaması yaparak büyüme rejimine geçiş yapmaktadır. Her iki rejimde de evre sayısı çoktur. Büyüme rejiminde ortalama kalma süresinin daha uzun olması, büyüme rejiminin daha kararlı olduğunu göstermektedir. Tahmin edilen modelin katsayıları ve geçiş olasılıkları incelendikten sonra rejim geçiş grafiği Şekil 2'de verilmiş̧ir.

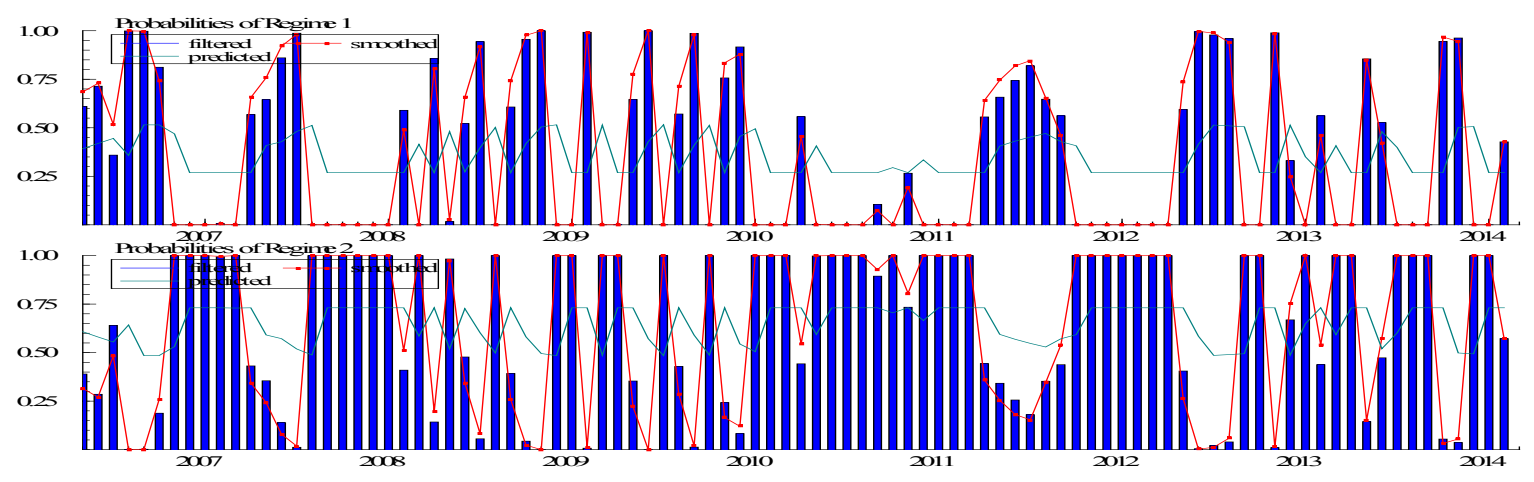

Şekil 2: $\triangle L S \ddot{U} E-\triangle L B E N$ için rejim grafiği

Grafikler bir arada ele alındığında; petroldeki yüksek oynaklıkların kriz rejimince (rejim 1), düşük oynaklığın ise büyüme rejimince (rejim 2) yakalandığı görülmektedir. Tahmin edilen modelin katsayıları ve geçiş olasılıkları ve rejim dönüm tarihleri incelendikten sonra etki tepki fonksiyonları tahmin edilmiş $\triangle L S \ddot{U} E-\triangle L P E T$ için etki tepki grafiği Şekil 3'te verilmiştir.
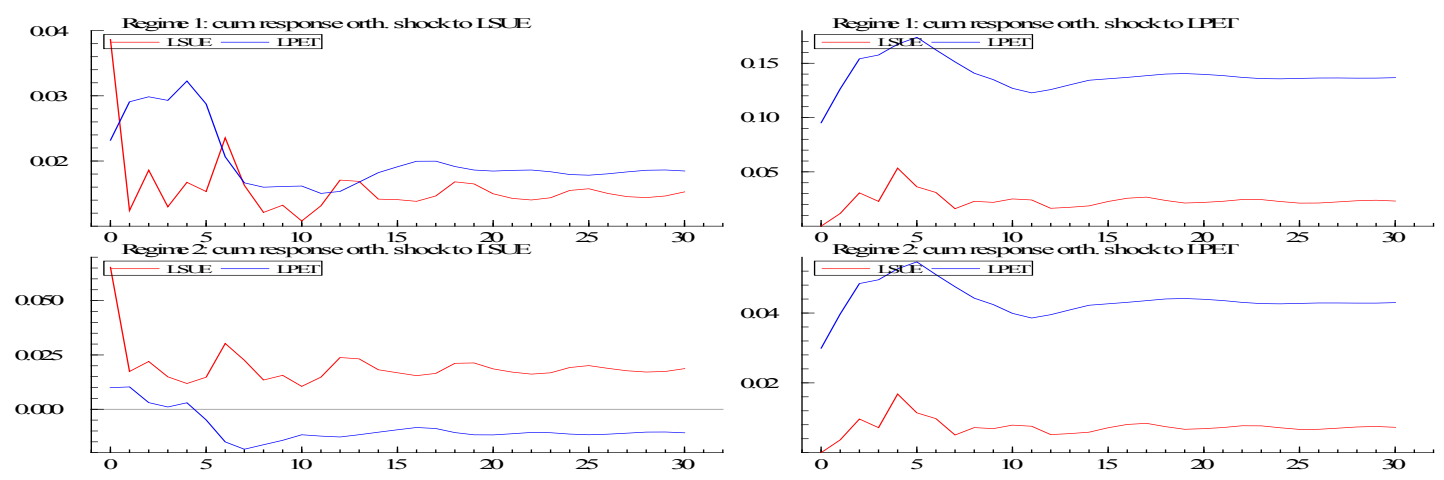

Şekil 3: $\triangle L S U ̈ E-\triangle L P E T$ için etki tepki fonksiyonu grafiği 
1. rejimde, petrol fiyatlarında bir şok etkisi meydana geldiğinde $\Delta L S \ddot{U} E$, 2. aya kadar bir artışla tepki vermiş, 3. ayda çok az bir azalma, 4. aya kadar artış, 7. aya kadar azalma şeklinde tepki vererek 20. aya kadar küçük dalgalanmalarla tepkisini sürdürmüştür. Ancak bu artış ve azalmaların tümü 0.02 ile 0.05 bandı içinde pozitif değerler ile olmuştur. Grafikte 30 ay boyunca petrol fiyat şokuna pozitif yönlü tepki veren $\Delta L S \ddot{U} E$ 'nin, eski düzeyinin üstünde yeni bir dengede devam ettiği görülmektedir. Bu da sanayi üretiminin petrol fiyat artışlarına karşıık mark-up fiyatlaması nedeni ile artışını sürdürebildiği ve petrol fiyat artışlarının $\triangle L S U ̈ E$ 'ye uzun ve kısa dönemde olumsuz bir etkisi- nin olmadığı şeklinde ifade edilebilir. Rejim 2'de petrol fiyatında bir şok etkisi meydana geldiğinde sanayi üretim endeksi, kriz rejimindekine benzer bir tepki vermektedir. Burada benzer hareketin nedeni, firmaların mark-up fiyatlama izlemesine dayandırılabilir. Sonuç olarak, enflasyon hedeflemesi rejimi altında petrol fiyat artışlarının $\triangle L S \ddot{U} E$ üzerinde azaltıcı bir etkisinin olmadığı, tam tersine mark-up fiyatlama nedeni ile artış yönünde etkisi olduğu ortaya konulmaktadır. Ancak bunun enflasyonu arttırıcı etkisi olduğu da görülmektedir. $\triangle L S U ̈ E-\triangle L B E N$ için etki tepki grafiği Şekil 4'te verilmiştir.

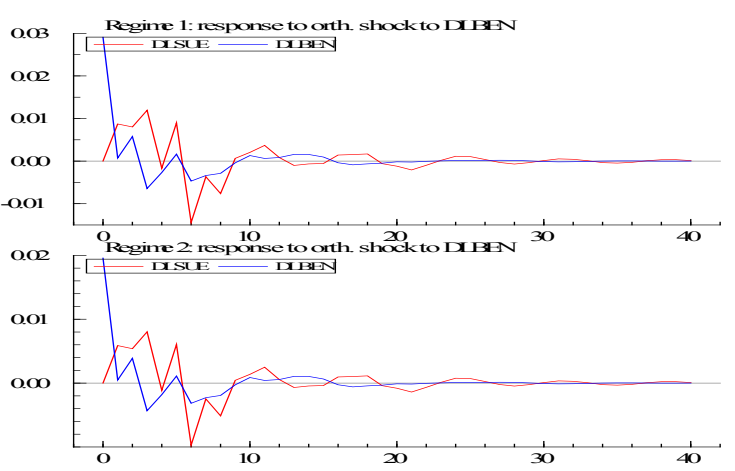

Şekil 4: $\triangle L S U ̈ E-\triangle L B E N$ için etki tepki fonksiyonu grafiği

Rejimde benzin fiyatında ani bir şok meydana geldiğinde $\triangle L S U ̈ E$, 1ve 2. aylarda pozitif, 3. ve 4. aylarda negatif, 5. ayda çok yüksek ve pozitif, 7-9. aylarda negatif, 10-12. aylarda pozitif tepki vermiştir. Daha sonraki dönemde artış ve azalışlarla 40. aya kadar tepkisini sürdürmüştür. Ancak bu artış ve azalmaların tümü +0.015 ve -0.015 bandı arasında olmuştur. Bu sonuç sanayi üretiminin benzin fiyat artışlarına uzun dönemli tepkisinin olduğunu ortaya koymaktadır. Bunun nedeni de benzin fiyatlarında ayarlama adı altında yapılan düzenlemelerin sıklığına bağlanabilir. Mark-up fiyatlama yapıp sanayi üretiminde artış sağlanırken yapılan fiyat ayarlamaları nedeni ile inişli çıkışlı tepki gözlenmiştir. Benzin fiyat artışlarının $\triangle L S U ̈ E$ 'ye kısa dönemde olumlu katkısı olurken, uzun dönemde artış ve azalış şeklinde etkisi olmuştur. 2. Rejimde benzin fiyatında ani bir şok meydana geldiğinde $\triangle L S U ̈ E$, kriz rejimine benzer bir tepki vermektedir. Burada benzer hareketin nedeni, firmaların mark-up fiyatlama izlemesine dayandırılabilir. Sonuç olarak, enflasyon hedeflemesi rejimi altında benzin fiyat artışlarının $\triangle L S U ̈ E$ üzerinde hem arttırıcı hem de azaltıcı etkisinin olduğu söylenebilir. Bu da kısa sürede mark-up fiyatlaması nedeni ile üretimdeki büyüme olumsuz etkilenmese de, uzun süreli olarak benzin fiyat artışlarının $\triangle L S \ddot{U} E$ 'ye olumsuz etkisinin olacağı şeklinde yorumlanabilir. Etki tepki grafikleri incelendikten sonra çalışmanın bundan sonraki aşamasında tahmin edilen modeller öngörü amaçlı kullanılmıştır.

Krolzig (2000) diğer doğrusal olmayan modellerin öngörüde başarısız olduğuna değinerek, MS-VAR modellerinin bu modellerden farklı olarak otoregresif parametrelerin rejimden bağımsız olması durumunda çok basamaklı öngörüye izin verdiğini, bu nedenle öngörü performansının yüksek olduğunu belirtmiştir. Krolzig, Marcellino ve Mizon (2001), İngiltere'de emek piyasası için yaptıkları çalışmada üç rejimli MS-VAR/VECM modelinin doğrusal ve doğrusal olmayan modellerden daha başarılı öngörü performansı sağladığını ortaya koymuşlardır. Binner, Elger, Nilsson ve Tepper (2005) vektör rejim değişim modeli, yapay sinir ağı modeli ve doğrusal VAR modelinin öngörü başarılarını kıyaslamış, iki doğrusal olmayan modelin öngörü sonuçları birbirine benzerken, her ikisinin de doğrusal VAR modelinden daha iyi öngörü performansı sergilediğini göstermişlerdir. Kosater ve Mosler (2006) da Almanya elektrik spot piyasası için yaptığı analizlerde MS-VAR modelinin doğrusal modellerden daha iyi sonuç verdiğini ortaya koymuşlardır.

“TCMB'nin "enflasyon ve diğer ekonomik büyüklüklere ilişkin öngörüleri, gelecekte karşılaşılabilecek enflasyonist baskılara karşı uyarı niteliği taşıyacak ve enflasyonla mücadelede önemli yere sahip olan faiz kararlarının alınmasında yol gösterici olacaktır" ifadesi, bu modellerin öngörü amaçlı olarak kullanılmasının önemini ve gerekliliğini ortaya koymaktadır. Bu nedenle modeller öngörü amaçlı kullanılmış ve SÜE-PET için çizilen 2014:3-2014:12 dönemi için öngörü grafiği Şekil 5 'te verilmiştir. 


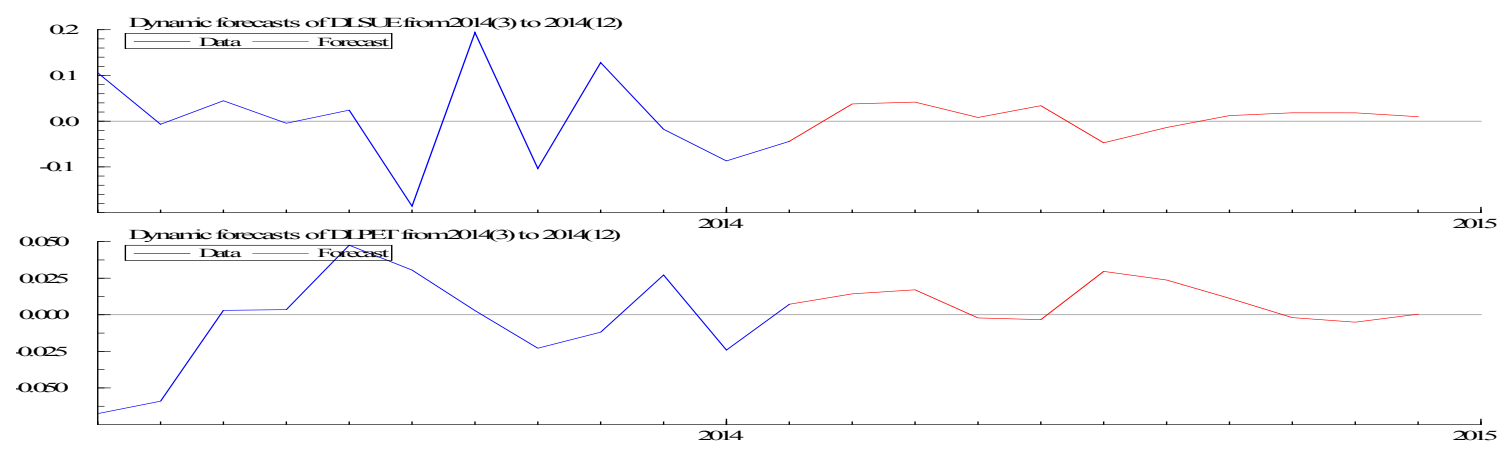

Şekil 5: $\triangle L S \ddot{U} E-\triangle L P E T$ için 2014:3-2014:12 dönemi öngörüsü

Yapılan dinamik öngörü, sanayi üretim endeksinin büyümesinin 2014'ün 3. ayda pozitif olacağını; 4., 5. ve 6. aylarda inişli çıkışlı ancak pozitif değerli iken 7. ve 8. aylarda negatif değer alacağını; 9. ayda pozitife geçerek 10. aydan itibaren de eski düzeyinin üstünde paralel devam edeceğini göstermektedir. $\triangle L S \ddot{U} E$ için yapılan dinamik öngörü sonucunda $\triangle L S U ̈ E$ 'nin azalma ve artma şeklinde bir salınımla devam edeceği, 9. aydan itibaren yıl sonuna kadar eski düzeyinin biraz üstünde bir değer yaratacağı görülmüştür.

Yapılan dinamik öngörü, ham petrol fiyatlarındaki değişmenin 2014'ün 2 ayında itibaren küçük oranlıda olsa artışa geçeceğini, 3. ve 4. aylarda pozitif değerli olacağını; 5. ve 6. aylarda küçük azalma göstererek negatif değerli olacağını; ardından 7. ayda hızla artış göstereceğini; 7. aya göre azalma ile birlikte 8. ve 9. aylarda pozitif değer alacağını, 10. ve 11. aylarda azalarak eski düzeyinin altına ineceğini, 12. ayda ise eski düzeyine tekrar döneceğini göstermektedir. Petrol fiyatı için yapılan dinamik öngörü sonucunda petrol fiyatlarındaki değişmelerin yine artış ve azalış şeklinde devam eden bir salım göstererek 7. ayda en yüksek düzeyde olacağını, yıl sonunda ise eski düzeyine döneceği görülmüştür. $\triangle L S \ddot{U} E-\triangle L B E N$ için çizilen 2014:3-2014:12 dönemi için öngörü grafiği Şekil 6'da verilmiştir.

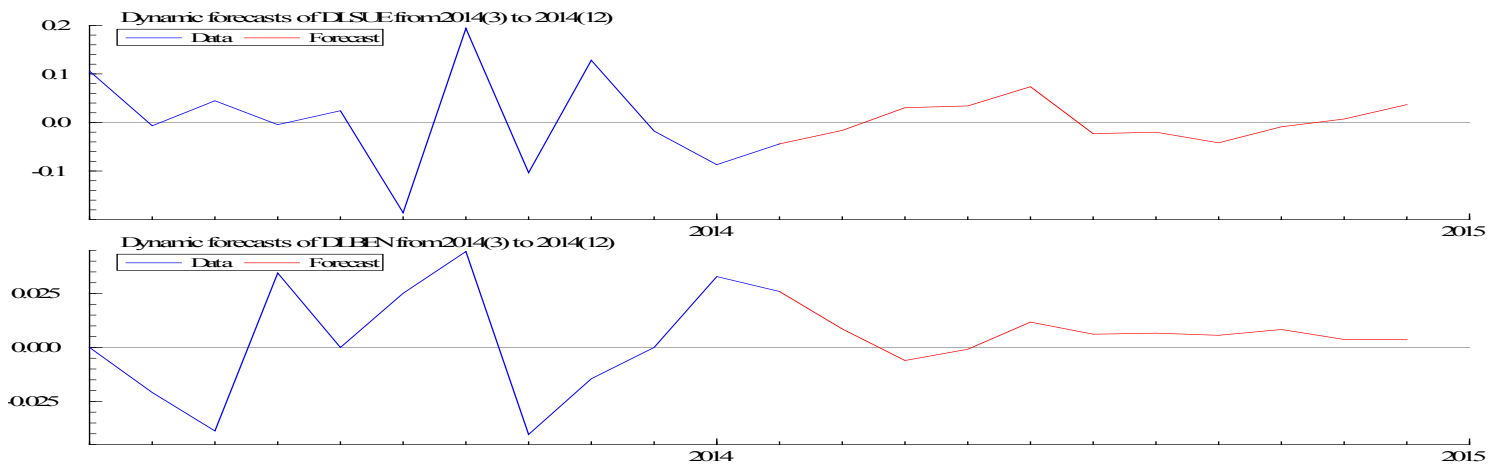

Şekil 6: $\triangle L S \ddot{U} E-\triangle L B E N$ için 2014:3-2014:12 dönemi öngörüsü

Yapılan dinamik öngörü, benzin fiyatındaki değişmelerinin 2014'ün 3. ayında pozitif olduğunu, 4. ayda negatif değer alacağını; 5. ayda hala negatif ancak 0'a çok yakın bir değerde iken 6. ayda artacağı ve bu artışın pozitif yönlü ve yatay bir seyirde 12. aya kadar süreceğini göstermektedir. Sonuç, 12. ayda eski düzeyinin üstünde bir değer alacağını göstermektedir. Sanayi üretim endeksi büyüme oranının ise 2. aydan itibaren artarak 3. dönemde 0'a çok yakın negatif değerde olacağı; 4., 5. ve 6. aylarda pozitif değer alacağı, 6. aydan itibaren azalacağı; 7. aydan itibaren 10. aya kadar negatif iken 11. ayda eski düzeyine yakın ancak hala negatif iken 12. ayda eski düzeyinin üstünde bir değere ulaşacağı görülmektedir. $\triangle L S U ̈ E$ için yapılan dinamik öngörü sonucunda $\triangle L S \ddot{U} E$ büyüme oranının azalma ve artma şeklinde bir salınımla devam edeceği, 2014 yılı sonunda eski düzeyinin biraz üstünde bir değer yaratacağı öngörülmüştür.

Yapılan analizler ve öngörü sonucunda ne petrol fiyat artışlarının ne de benzin fiyat artışlarının $\triangle L S U ̈ E$ 'yi azaltıcı yönde bir baskı yaratmayacağı ortaya konulmuştur. Ancak bu bulguların, toplam sektör için geçerli olduğu, bu nedenle tüm alt sektörlerde benzer etkiyi yaratacağı şeklinde genellenmesinin hatalı olabileceği ifade edilebilir. Özellikle petrol ürünlerine bağımlılığı yüksek olan sektörlerde sonuçların farklı olabileceği göz önünde bulundurulmalıdır. 


\section{Sonuç ve Değerlendirme}

Bu çalışmada Türkiye'de açık enflasyon hedeflemesi uygulanmasının etkisinin görülmeye başlandığı 2006'dan 2014 yılı başına kadar geçen dönemde ham petrol fiyatlarındaki değişmeler ile yurtiçi benzin fiyat değişmelerinin SÜE üzerindeki etkisi MS-VAR modelleri ile araştırılmıştır. Tüm değişkenler için iki rejimin varlığı belirlenmiştir. Farklı rejimlerin olması, serilerin her rejimde farklı farklı davranışlarının olduğunu göstermiştir. Kriz döneminde petrol ve benzin fiyatlarının oynaklığının, sanayi üretimine göre daha fazla, ancak büyüme rejiminde sanayi üretiminin oynaklığının daha fazla olduğu görülmüştür. Benzin fiyatlarının 1. rejimde oynaklığı, sanayi üretiminin oynaklığına göre daha fazla iken 2. rejimde sanayi üretiminin oynaklığı benzin fiyatlarındaki oynaklığın 4 katıdır. Bunun nedeninin kriz rejiminde, krizin petrol fiyatlarından veya benzin fiyatlarından kaynaklanması olduğu sonucuna varılmıştır. Büyüme rejiminde ise petrol ve benzin fiyatlarının oynaklığı düşerken, kriz rejiminden büyüme rejimine geçen ekonomide üretimin arttığı görülmüştür.

Yapılan analizler ayrıca petrol ve benzinin fiyat değişmelerinin sanayi üretimine etkilerinin farklı olduğunu göstermiştir. Petrol fiyatlarındaki değişmelerin sanayi üretimine etkisinin 1 ve 2 . dönemlerde negatif ve istatistiksel olarak anlamli; 3 ve 4 . dönemlerde pozitif ve istatistiksel anlamlı olduğu, 7. dönemde ise etki, negatif ve istatistiksel olduğu belirlenmiştir. Benzin fiyatlarındaki değişmelerin sanayi üretimine 1 . dönemden başlamak üzere 5 dönem boyunca pozitif ve istatistiksel anlamlı etkisinin olduğu ve sadece 7 . dönemde negatif yönlü ve önemli etkisi olduğu bulgusuna ulaşılmıştır. Bunlara dayanarak: petrol fiyatlarındaki değişmeye sanayinin ilk 2 ayda uyum sağlayamadığı ve azalma yönünde tepki verdiği, ancak 3 . dönemden itibaren etkinin yönünün pozitif olduğu ve gecikme etkisi ile sanayi üretiminde mark-up fiyatlaması uyguladığı kabul edilmiştir. Ayrıca düşük büyüme rejiminde iken yüksek büyüme rejimine geçme olasılıklarının yakın olması, petrol fiyatlarındaki ani artışların sanayi üretiminde kriz dönemi etkisi yarattığı sonucunu ortaya çıkarmıştır. Benzin fiyatlarındaki değişmeye ise sanayinin hemen uyum sağladığı ve mark-up uygulamasına hemen gidildiği görülmüştür.

Bu çalışmanın sonucunda, TCMB politika yapıcılarının petrol ve benzin fiyatlarının sanayi üretimi gibi makroekonomik değişkenlere geçiş etkisini göz ardı etmemeleri gerektiğini ortaya koymuştur. Çünkü mark-up fiyatlama nedeni ile fiyatlar genel düzeyindeki yükselme, enflasyon hedeflerinde bozucu etki yaratacaktır. 


\section{Kaynaklar}

Alper, C.E. ve Torul, O. (2008). Oil Prices, aggregate economic activity and global liquidity conditions: evidence from Turkey. Economics Bulletin, 17(4), 1-8.

Ashley, R. ve Tsang, K.P. (2013). The Oil Price-Macroeconomy Relationship: Does Persistence Matter?. Araştırma raporu. USA.

Barisik, S. ve Yayar, R. (2012). Econometric Analysis of factors affecting industrial production index. Íktisat, $\dot{I}_{\xi}$ letme ve Finans, 27(316), 53-70.

Binner, J. M., Elger, T., Nilsson, B. ve Tepper, J. A. (2005). Tools for non-linear time series forecasting in economics-An empirical comparison of regime switching vector autoregressive models and recurrent neural networks. Advances in Econometrics, 19, 71-91.

Blanchard, O. J. ve Gali, J. (2007). The Macroeconomic Effects of Oil Shocks: Why are the 2000s so different from the 1970s? Araştırma Raporu. USA: National Bureau of Economic Research.

Cobo-Reyes, R. ve Perez Quiros, G. (2005). The effect of oil price on industrial production and on stock returns. Araştırma raporu 05/18. Spain: Universidad de Granada

Cunado, J. ve Pérez de Gracia, F. (2005). Oil prices, economic activity and inflation: evidence for some Asian countries. The Quarterly Review of Economics and Finance, 45(1), 65-83.

Dempster, A. P., Laird, N. M. ve Rubin, D. B. (1977). Maximum likelihood from incomplete data via the EM algorithm. Journal of the Royal Statistical Society. Series B (Methodological), 1-38.

Ekşi, İ. H., Izg1, B. B ve Şentürk, M. (2011). Reconsidering the Relationship between Oil Prices and Industrial Production: Testing for Cointegration in some of the OECD Countries. Eurasian Journal of Business and Economics, 4(8), 1-12.

Fukunaga, I., Hirakata, N. ve Sudo, N. (2010). The effects of oil price changes on the industry-level production and prices in the US and Japan. Araştırma raporu 15791. USA: National Bureau of Economic Research.

Hall, S. G., Psaradakis, Z. ve Sola, M. (1999). Detecting periodically collapsing bubbles: a Markov-switching unit root test. Journal of Applied Econometrics, 14(2), 143154.

Hamilton, J. D. (1988). Are the macroeconomic effects of oil-price changes symmetric?: A comment. Carnegie-Rochester Conference Series on Public Policy 28, 369-378.

Hamilton, J. D. (1989). A new approach to the economic analysis of nonstationary time series and the business cycle. Econometrica: Journal of the Econometric Society, 357384 .

Hamilton, J. D. ve Herrera, A. M. (2004). Comment: oil shocks and aggregate macroeconomic behavior: the role of monetary policy. Journal of Money, Credit and Banking, 265-286.
Herrera, A. M., Lagalo, L. G. ve Wada, T. (2011). Oil price shocks and industrial production: Is the relationship linear?. Macroeconomic Dynamics, 15(S3), 472-497.

Kilian, L. ve Vigfusson, R. J. (2011). Are the responses of the U.S. economy asymmetric in energy price increases and decreases?. Quantitative Economics, 2(3), 419-453.

Jiménez-Rodríguez, R. ve Sanchez, M. (2005). Oil price shocks and real GDP growth: empirical evidence for some OECD countries. Applied economics,37(2), 201-228.

Jimenez-Rodriguez, R. (2008). The impact of oil price shocks: evidence from the industries of six OECD countries. Energy Economics, 30(6), 3095-3108.

Kalecki, M. (1954). Theory of Economic Dynamics: An Essay on Cyclical and Long-run Changes in Capitalist Economy. Araştırma raporu. George Allen \& Unwin.

Kosater, P. ve Mosler, K. (2006). Can Markov regimeswitching models improve power-price forecasts? Evidence from German daily power prices. Applied Energy, 83(9), 943-958.

Krolzig, H. M. (1997). Markov-switching vector autoregressions(modelling, statistical interference, and application to business cycle analysis). Lecture notes in economics and mathematical systems.

Krolzig, H. M. (1998). Econometric modelling of Markov-switching vector autoregressions using MSVAR for $\mathrm{Ox}$.

Krolzig, H. M. (2000). Predicting Markov-switching vector autoregressive processes. Araştırma raporu. UK: Nuffield College.

Krolzig, H. M. (2000). Predicting Markov-switching vector autoregressive processes. Araştırma raporu. UK: Nuffield College.

Krolzig, H. M. (2001). General-to-specific reductions of vector autoregressive processes. Econometric Studies-A Festschrift in Honour of Joachim Frohn, 129-157.

Krolzig, H. M. (2006). Impulse-Response Analysis in Markov Switching Vector Autoregressive Models. [Erişim adresi\}: https://editorialexpress. com/cgibin/conferenceldownload. cgi.

Krolzig, H. M., Marcellino, M. ve Mizon, G. E. (2002). A Markov-switching vector equilibrium correction model of the UK labour market. In Advances in MarkovSwitching Models, 91-112.

Mork, K. A., Olsen, Ø. ve Mysen, H. T. (1994). Macroeconomic responses to oil price increases and decreases in seven OECD countries. The Energy Journal, 15(4), 19-35.

Cuñado ve Pérez de Gracia (2003). [Erişim adresi]: http://www.aeefi.com/RePEc/pdfldefi01-02.pdf

Yaylali, M. ve Lebe, F. (2012). İthal Ham Petrol Fiyatlarının Türkiye'deki Makroekonomik Aktiviteler Üzerindeki Etkisi. Marmara Üniversitesi IIBF Dergisi, 32(1), 43-68.

Zhang, D. (2008). Oil shock and economic growth in Japan: A nonlinear approach. Energy Economics, 30(5), 2374-2390. 